Pacific Journal of Mathematics

A NOTE ON RECURSIVELY DEFINED ORTHOGONAL 


\title{
A NOTE ON RECURSIVELY DEFINED ORTHOGONAL POLYNOMIALS
}

\author{
DANIEL P. MAKI
}

Let $\left\{a_{i}\right\}_{i=0}^{\infty}$ and $\left\{b_{i}\right\}_{i=0}^{\infty}$ be real sequences and suppose the $b_{i}, \mathbf{s}$ are all positive. Define a sequence of polynomials $\left\{P_{i}(x)\right\}_{i=0}^{\infty}$ as follows: $P_{0}(x)=1, P_{1}(x)=\left(x-a_{0}\right) / b_{0}$, and for $n \geqq 1$

$$
b_{n} P_{n+1}(x)=\left(x-a_{n}\right) P_{n}(x)-b_{n-1} P_{n-1}(x) \text {. }
$$

Favard showed that the polynomials $\left\{P_{\imath}(x)\right\}$ are orthonormal with respect to a bounded increasing function $\psi$ defined on $(-\infty,+\infty)$. This note generalizes recent constructive results which deal with connections between the two sequences $\left\{a_{\imath}\right\}$ and $\left\{b_{i}\right\}$ and the spectrum of $\psi$. (The spectrum of $\psi$ is the set $S(\psi)=\{\lambda: \psi(\lambda+\varepsilon)-\psi(\lambda-\varepsilon)>0$ for all $\varepsilon>0\}$.) It is shown that if $b_{i} \rightarrow 0$ then every limit point of the sequence $\left\{a_{i}\right\}$ is in $S(\psi)$.

2. Preliminaries, In order to use theorems from functional analysis, consider the space $\mathscr{L}^{2}(\psi)=\left\{f: \int_{-\infty}^{+\infty} f^{2} d \psi<\infty\right\}$. This is a Hilbert space where the inner product is gived by $(f, g)=\int f g d \psi$ and where we identify all functions which agree on $S(\psi)$. In [2], (p. 215), Carleman showed that the condition $\sum 1 / \sqrt{b_{i}}=\infty$ implies that when $\psi$ is normalized to be continuous from the left and to have $\psi(-\infty)=0, \psi(+)=1$, then it is unique. In [6], M. Riesz showed that if $\psi$ is essentially unique then Parseval's relation holds for the orthonormal set $\left\{P_{i}\right\}$ in the space $\mathscr{L}^{2}(\psi)$. Hence the set $\left\{P_{i}\right\}$ is dense in this space.

We now make the assumption that $\lim b_{i}=0$. Combining the Carleman result and the Riesz result we see that $\psi$ is essentially unique and the polynomials $\left\{P_{i}\right\}$ are a dense set in $\mathscr{L}^{2}(\psi)$. Using this information we define an operator $A$ on a dense subset of $\mathscr{L}^{2}(\psi)$. The domain of $A$ is the set of all functions $f$ which are in $\mathscr{L}^{2}(\psi)$ and for which $x f$ is also in $\mathscr{L}^{2}(\psi)$. We take $A$ to be the self-adjoint operator defined by $(A f)(x)=x f(x)$. By inspection of $(*)$ we see that for $i=1,2,3, \cdots$ we have

$$
A\left(P_{i}\right)=b_{i-1} P_{i-1}+a_{i} P_{i}+b_{i} P_{i+1}
$$

We call $A$ the operator associated with the sequences $\left\{a_{i}\right\}$ and $\left\{b_{i}\right\}$.

3. Theorems. Let $\sigma(A)$ be the spectrum of the operator $A$, i.e., all points $\lambda$ where $A-\lambda I$ does not have a bounded inverse. Then we have the following: 
LEMMA. $\sigma(A) \subset S(\psi)$.

Proof. Let $\lambda \in \sigma(A)$. Since $A$ is self-adjoint, $\lambda$ is in the approximate point spectrum of $A$. Hence there exists a sequence $\left\{f_{n}\right\}$ in the domain of $A$ satisfying $\left\|f_{n}\right\|=1, n=1,2, \cdots$, and $\left\|(A-\lambda) f_{n}\right\| \rightarrow 0$ as $n \rightarrow \infty$. Now by the definition of the norm in $\mathscr{L}^{2}(\psi)$ this means $\int_{-\infty}^{+\infty} f_{n}^{2} d \psi=1, n=1,2, \cdots$, and $\int_{-\infty}^{+\infty}(x-\lambda)^{2} f_{n}^{2} d \psi \rightarrow 0$ as $n \rightarrow \infty$. Now suppose $\lambda \notin S(\psi)$. Then there exists $\varepsilon>0$ such that

$$
\psi(\lambda+\varepsilon)-\psi(\lambda-\varepsilon)=0
$$

Thus $\psi$ has no mass in the interval $[\lambda-\varepsilon, \lambda+\varepsilon]$, and we have

$$
\int_{-\infty}^{\lambda-\varepsilon} f_{n}^{2} d \psi+\int_{\lambda+\varepsilon}^{+\infty} f_{n}^{2} d \psi=1, \quad n=1,2, \cdots,
$$

and

$$
\int_{+\infty}^{\lambda-\varepsilon}(x-\lambda)^{2} f_{n}^{2} d \psi+\int_{\lambda+\varepsilon}^{+\infty}(x-\lambda)^{2} f_{n}^{2} \psi \rightarrow 0 \text { as } n \rightarrow \infty .
$$

But these are contradictory since

$$
\begin{aligned}
& \int_{-\infty}^{\lambda-\varepsilon}(x-\lambda)^{2} f_{n}^{2} d \psi+\int_{\lambda+\varepsilon}^{+\infty}(x-\lambda)^{2} f_{n}^{2} d \psi \\
& \geqq \varepsilon^{2}\left[\int_{-\infty}^{\lambda-\varepsilon} f_{n}^{2} d \psi+\int_{\lambda+\varepsilon}^{+\infty} f_{n}^{2} d \psi\right]=\varepsilon^{2} .
\end{aligned}
$$

This completes the proof.

We are now ready for our result about $S(\psi)$. It is motivated by the results in [5] where we constructed $\psi$ in the case where $b_{i} \rightarrow 0$ and $\left\{a_{i}\right\}$ has only a finite number of limit points.

THEOREM. Let the sequence of polynomials $\left\{P_{i}\right\}_{0}^{\infty}$ be recursively defined by $(*)$ and assume $b_{i}>0$ for each $i$ and $b_{i} \rightarrow 0$. Then each limit point of the sequence $\left\{a_{i}\right\}$ is a point of the spectrum of the associated distribution function $\psi$.

Proof. From the above lemma it suffices to show that each limit point of the sequence $\left\{a_{i}\right\}$ is in $\sigma(A)$. Thus let $\lambda$ be a limit point of $\left\{a_{i}\right\}$ and suppose $\left\{a_{i(n)}\right\}$ is a subsequence converging to $\lambda$. Next let $f_{n}(x)=P_{i(n)}(x), n=1,2,3, \cdots$. By the defining relation $(*)$ and by the definition of $A$, we have

$$
\begin{aligned}
\|(A & -\lambda) f_{n}\left\|^{2}=\right\|(x-\lambda) P_{i(n)} \|^{2} \\
& =\int_{-\infty}^{+\infty}\left(b_{i(n)-1} P_{i(n)-1}+\left(a_{i(n)}-\lambda\right) P_{i(n)}+b_{i(n)} P_{i(n)+1}\right)^{2} d \psi \\
& =b_{i(n)-1}^{2}+\left(a_{i(n)}-\lambda\right)^{2}+b_{i(n)}^{2} .
\end{aligned}
$$


Now $b_{i} \rightarrow 0$ and $a_{i(n)} \rightarrow \lambda$, so we see $\left\|(A-\lambda) f_{n}\right\|^{2} \rightarrow 0$ as $n \rightarrow \infty$. Moreover $\left\|f_{n}\right\|=\left\|P_{i(n)}\right\|=1$, so $\lambda \in \sigma(A)$ and the proof is complete.

REMARK. If we choose the $a_{i}$ 's to be dense in the real line, for example any enumeration of the rationals, then for every set of $b_{i}$ 's satisfying $b_{i} \rightarrow 0$ we have $S(\psi)=(-\infty,+\infty)$.

Conjecture. The converse of the above theorem does not hold since in [5] our construction exhibited points of $S(\psi)$ which were not limit points of $\left\{a_{i}\right\}$. However each limit point of $S(\psi)$ was a limit point of $\left\{a_{i}\right\}$. So it seems reasonable to conjecture that when $b_{i} \rightarrow 0, \lambda$ is a limit point of $S(\psi)$ if and only if $\lambda$ is a limit point of $\left\{a_{i}\right\}$.

\section{REFERENCES}

1. N. I. Akhiezer and I. M. Glazman, Theory of linear operators in Hilbert space, Vol. I, Ungar, New York, 1961.

2. T. Carleman, Sur Les Equations Integrales Singular A Noyau Reel et Symetreque, Uppsala, 1928.

3. J. Favard, Sur les polynomes de Tchebichiff, C. R. Acand. Sci. Paris 200 (1935), 2052-2053.

4. J. L. Goldberg, Some polynomials orthogonal over a denumerable set, Pacific J. Math. 15 (1965), 1171-1186.

5. D. P. Maki, On constructing distribution functions: A bounded denumerable spectrum with $n$ limit points, Pacific J. Math. 22 (1967), 431-452.

6. M. Riesz, Sur les probleme des moments et le theoreme de Parseval correspondant, Acta Litterarum ac Scientearum (Szeged) (1922-1923), 209-225.

Received January 12, 1968.

INDIANA UNIVERSITY

BLOOMINGTON, INDIANA 



\section{PACIFIC JOURNAL OF MATHEMATICS}

\section{EDITORS}

\author{
H. ROYDEN \\ Stanford University \\ Stanford, California \\ R. R Phelps \\ University of Washington \\ Seattle, Washington 98105
}

\author{
J. Dugundui \\ Department of Mathematics \\ University of Southern California \\ Los Angeles, California 90007
}

RICHARD ARENS

University of California

Los Angeles, California 90024

\section{ASSOCIATE EDITORS}
E. F. BeCKENBACH
B. H. NeUmanN
F. WolF
K. YosidA

\section{SUPPORTING INSTITUTIONS}

\author{
UNIVERSITY OF BRITISH COLUMBIA \\ CALIFORNIA INSTITUTE OF TECHNOLOGY \\ UNIVERSITY OF CALIFORNIA \\ MONTANA STATE UNIVERSITY \\ UNIVERSITY OF NEVADA \\ NEW MEXICO STATE UNIVERSITY \\ OREGON STATE UNIVERSITY \\ UNIVERSITY OF OREGON \\ OSAKA UNIVERSITY \\ UNIVERSITY OF SOUTHERN CALIFORNIA
}

\author{
STANFORD UNIVERSITY \\ UNIVERSITY OF TOKYO \\ UNIVERSITY OF UTAH \\ WASHINGTON STATE UNIVERSITY \\ UNIVERSITY OF WASHINGTON

$* * * * *$
AMERICAN MATHEMATICAL SOCIETY
CHEVRON RESEARCH CORPORATION
TRW SYSTEMS
NAVAL WEAPONS CENTER

The Supporting Institutions listed above contribute to the cost of publication of this Journal, but they are not owners or publishers and have no responsibility for its content or policies.

Mathematical papers intended for publication in the Pacific Journal of Mathematics should be in typed form or offset-reproduced, double spaced with large margins. Underline Greek letters in red, German in green, and script in blue. The first paragraph or two must be capable of being used separately as a synopsis of the entire paper. It should not contain references to the bibliography. Manuscripts, in duplicate if possible, may be sent to any one of the four editors. Please classify according to the scheme of Math. Rev. 36, 1539-1546. All other communications to the editors should be addressed to the managing editor, Richard Arens, University of California, Los Angeles, California, 90024.

50 reprints are provided free for each article; additional copies may be obtained at cost in multiples of 50 .

The Pacific Journal of Mathematics is published monthly. Effective with Volume 16 the price per volume (3 numbers) is $\$ 8.00$; single issues, $\$ 3.00$. Special price for current issues to individual faculty members of supporting institutions and to individual members of the American Mathematical Society: $\$ 4.00$ per volume; single issues $\$ 1.50$. Back numbers are available.

Subscriptions, orders for back numbers, and changes of address should be sent to Pacific Journal of Mathematics, 103 Highland Boulevard, Berkeley, California, 94708.

PUBLISHED BY PACIFIC JOURNAL OF MATHEMATICS, A NON-PROFIT CORPORATION

Printed at Kokusai Bunken Insatsusha (International Academic Printing Co., Ltd.), 7-17. Fujimi 2-chome, Chiyoda-ku, Tokyo, Japan. 


\section{Pacific Journal of Mathematics}

Vol. 28, No. 3

May, 1969

Jon F. Carlson, Automorphisms of groups of similitudes over $F_{3} \ldots \ldots \ldots$

W. Wistar (William) Comfort, Neil Hindman and Stelios A. Negrepontis,

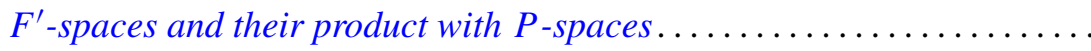

Archie Gail Gibson, Triples of operator-valued functions related to the unit

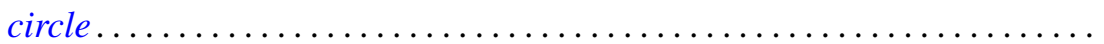

David Saul Gillman, Free curves in $E^{3}$

E. A. Heard and James Howard Wells, An interpolation problem for

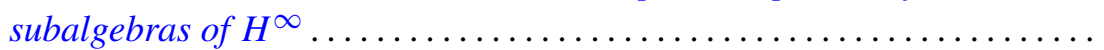

Albert Emerson Hurd, A uniqueness theorem for weak solutions of symmetric

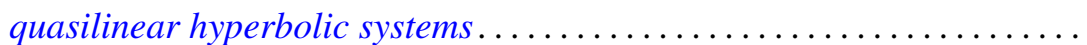

E. W. Johnson and J. P. Lediaev, Representable distributive Noether

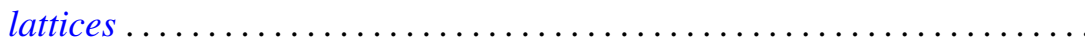

David G. Kendall, Incidence matrices, interval graphs and seriation in

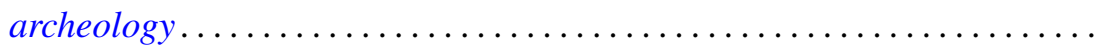
565

Robert Leroy Kruse, On the join of subnormal elements in a lattice ....... 571

D. B. Lahiri, Some restricted partition functions; Congruences modulo 3 .... 575

Norman D. Lane and Kamla Devi Singh, Strong cyclic, parabolic and conical differentiability........................................

William Franklin Lucas, Games with unique solutions that are

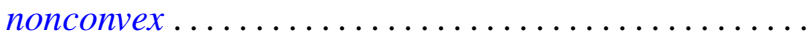

Eugene A. Maier, Representation of real numbers by generalized geometric series.

Daniel Paul Maki, A note on recursively defined orthogonal polynomials ...

Mark Mandelker, $F^{\prime}$-spaces and z-embedded subspaces ...

James R. McLaughlin and Justin Jesse Price, Comparison of Haar series with gaps with trigonometric series

Ernest A. Michael and A. H. Stone, Quotients of the space of irrationals ....

William H. Mills and Neal Zierler, On a conjecture of Golomb ...

J. N. Pandey, An extension of Haimo's form of Hankel convolutions ...

Terence John Reed, On the boundary correspondence of quasiconformal mappings of domains bounded by quasicircles...

Haskell Paul Rosenthal, A characterization of the linear sets satisfying Herz's criterion.

George Thomas Sallee, The maximal set of constant width in a lattice...

I. H. Sheth, On normaloid operators

James D. Stasheff, Torsion in BBSO ...

Billy Joe Thorne, A - P congruences on Baer semigroups.

Robert Breckenridge Warfield, Jr., Purity and algebraic compactness for

modules... 